\title{
A case study of the Rajasthan canal
}

\author{
RAMESHWAR D VARMA \\ Department of Civil Engineering, M.R. Engineering College, Jaipur 302017, India
}

\begin{abstract}
The study deals with the policy issues relevant to agriculture development in arid regions where water has a very high economic value. The experience gained in irrigation planning under such conditions in different parts of the world is described. The issues relevant for such a study are the level of technology, the cropping pattern, the area under cultivation and the size of the holdings. For the study of these issues a linear programming model maximizing returns, subject to land and water constraints, has been developed and is applied in the Rajasthan canal command area. The study concludes that agriculture and irrigation technology of a high level should be used to maximize benefits and production, which would also generate more employment.
\end{abstract}

Keywords. Irrigation planning; arid region; Linear programming model.

\section{Introduction}

About $36 \%$ of the total land area of the world is arid, housing only about $13 \%$ of the world's population. With the increasing population of the world the use of arid lands for the settlement of people, food production and other economic activities will increase. Although the experience of some arid lands (e.g., Arizona in the United States and Negev in Israel) has established that economic growth in such areas is possible through agriculture, it is generally believed that because of the acute shortage of water, agriculture may not be a very desirable sector for the economic development of such regions. Whether agriculture should be a primary activity or not, the extent of this activity in desert areas should be determined by formulating a desert development plan for the economic growth of the region, which should take into account the available resources and the expectations of the people. While formulating the plan it should be kept in mind that the delicate environmental balance of the area is easily disturbed and that the unplanned depletion of the productive resources of the region could be dangerous.

The issues involving agricultural development in an arid environment are quite different from those in a humid environment. The important factors for this difference are water shortage, low atmospheric humidity resulting in high rates of evaporation, different soil characteristics, low population density, uneven topography and high cost of regional infrastructure.

The most important input limiting agricultural development in arid lands is water. Water for agriculture is available in the form of precipitation or groundwater or surface water imported from other drainage basins. It can also be made available by treating and purifying waste water or by desalinating seawater; however such waters are usually too expensive to use for agriculture. Water in the form of precipitation is very meagre for sustaining plant life and its availability in quantity as well as in time is highly uncertain. It may become even more uncertain with the unpredictable changes that 
seem to be taking place in the world climates. Unless good water-harvesting techniques, which are usually capital-intensive, are used rain-fed agriculture will be a risky enterprise and the farmer will be tempted justifiably not to use the essential inputs thereby limiting agricultural production to a very low level. The situation can be improved by developing better predictive methods of rain-water availability and by extending insurance policies to the farmers against crop failures. Policies relating to this dry farming agricultural development involve decisions under risk and uncertainty and have not been considered further in this discussion.

The groundwater resources in arid lands are usually not replenishable. Mining of groundwater for a limited period for agricultural development has been used for some desert areas. However unless definite plans for replenishing these resources are in operation, mining the productive resources of an arid area usually leaves behind an exploited and impoverished resources base. The various issues involved in mining groundwater resources in an arid environment have been discussed by Domenico (1968).

Agricultural development in arid areas is mostly achieved by importing water from other areas. This water has a very high economic value and many policy issues such as the level of technology to be used, cropping pattern, area to be committed for agriculture and size of holdings are involved in its use for the agricultural development and the overall economic growth of the region. Some of these policy issues for the arid lands in India with particular reference to the arid areas commanded by the Rajasthan Canal Project in India are discussed in this paper.

\section{Experiences of some other countries}

\subsection{USA (Arizona)}

Most of Arizona state in the United States is arid. The average precipitation in most parts of the state is less than $50 \mathrm{~cm}$. But with proper planning and water resources management the state has been able to achieve substantial economic growth. The water scarcity was resolved by evolving a set of water-related institutions that would facilitate change in water development and use so that each unit of scarce water used will make its maximum contribution to economic well-being directly through its consumption and indirectly through its use in production (Kelso et al 1973). A solution to the problem was found not only in improving water supplies but, more important, in reducing water demands by encouraging change in the structure of the state economy and pattern of water uses.

\subsection{Israel}

Some of the policies followed by Israel in planning its irrigation system were included in the following development criteria (Wiener 1964).

(i) Intensive conservation of available water resources and design of projects to minimize losses.

(ii) A complex resources appraisal methodology.

(iii) Sophisticated management planning of uses of resources.

(iv) Selective use, where feasible, of substandard water for less sensitive uses.

(v) Minimizing (within economic reason) the quantity of water consumed per production unit. In agriculture this requires the proper choice of crops and the 
regions where they are to be grown, increasing efficiency in irrigation, artificial reduction of evaporation and evapotranspiration and seed selection.

Table 1 compares the yields at Arizona, Israel and Rajasthan, and also the average for India. The figures indicate the positive effect of proper planning and water resources management in agriculture in the arid regions of Arizona and Israel.

\subsection{USSR}

The New York Times (Anon 1977) reported that the largest canal of its kind in the world, constructed by the Russians, has transformed the economic and social life in Turkmenia, a Soviet Central Asian Republic lying just North of Iran and Afghanistan. More than $80 \%$ of Turkmenia is desert. The canal which presently extends $912 \mathrm{~km}$ will eventually be $1392 \mathrm{~km}$ long with the final section swinging southwest to Turkmenia's subtropical region while a smaller pipeline splits Northwest to carry water for drinking and industrial use. It has been reported that the canal has already paid for itself; Turkemenia's cotton production increased nearly five-fold over the last three decades to $1 \cdot 12$ million tonnes last year with at least half of this growth attributed to the canal. Increases in some other crops like fruit have been nearly as dramatic.

\section{Rajasthan canal project}

Conceived at the turn of the century to rejuvenate a part of the Indian desert, the Rajasthan Canal Project was formally launched some six decades later in 1958. It contemplates the conveyance of a portion of the Ravi-Beas run-off in Punjab for irrigating 1.15 million hectares of an assorted arid area of Rajasthan State in its districts of Ganganagar, Bikaner and Jaisalmer all bordering Pakistan. Under a treaty between India and Pakistan in 1960, an annual supply of more than $18500 \mathrm{~m} \mathrm{cu} \mathrm{m}$ has been made available to India in which Rajasthan will be entitled to about $9866 \mathrm{~m} \mathrm{cu} \mathrm{m}$. With the construction of the Pong Dam, assured monthly flows for the year are now available for the Rajasthan canal project (Rao 1975). The Rajasthan canal with a full supply capacity of about 530 cumecs ( 18700 cusecs) takes off from the Harike Barrage across the Sutlej. The total length of the canal is about $680 \mathrm{~km}$; the main canal and distributaries are to be lined (Irrigation Commission 1972). The conveyance losses in the main canal and distributaries are estimated to be $10 \%$. Water distribution losses in the field (on the farm) are estimated to be $20 \%$. Efforts are being made to reduce these losses by levelling the fields and lining the water courses. The irrigation intensity of the project is expected to be $130 \%$. The project is divided into two stages, the first stage commands an area of about 0.54 million hectares. The construction of the project is an engineering feat achieved by Indian engineers under extremely difficult environmental conditions. A map of Rajasthan showing its soils and the canal is given in figure 1.

Statistics of the arid land of Rajasthan, giving area, population and mean annual rainfall, are given in table 2 districtwise. This shows that the population density in the area commanded by the Rajasthan Canal is low and the project will induce migration of agricultural workers to the area and will provide self employment to the people already there. The existing cropping patterns in the various districts of the desert area of Rajasthan along with the adopted cropping pattern of the project are given in table 3. In this table the cropping pattern in the arid state of Arizona has also been given for 


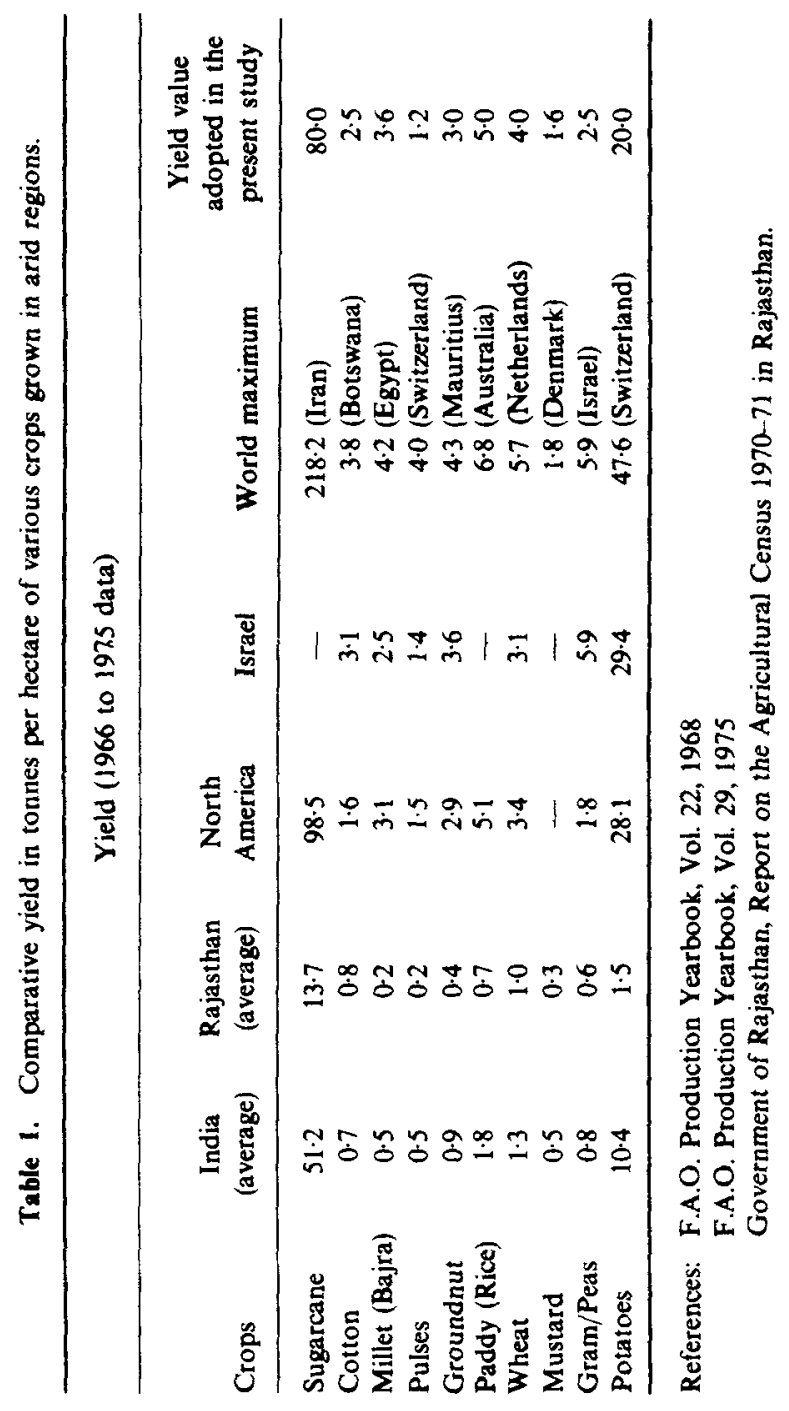




\section{LEGEND}

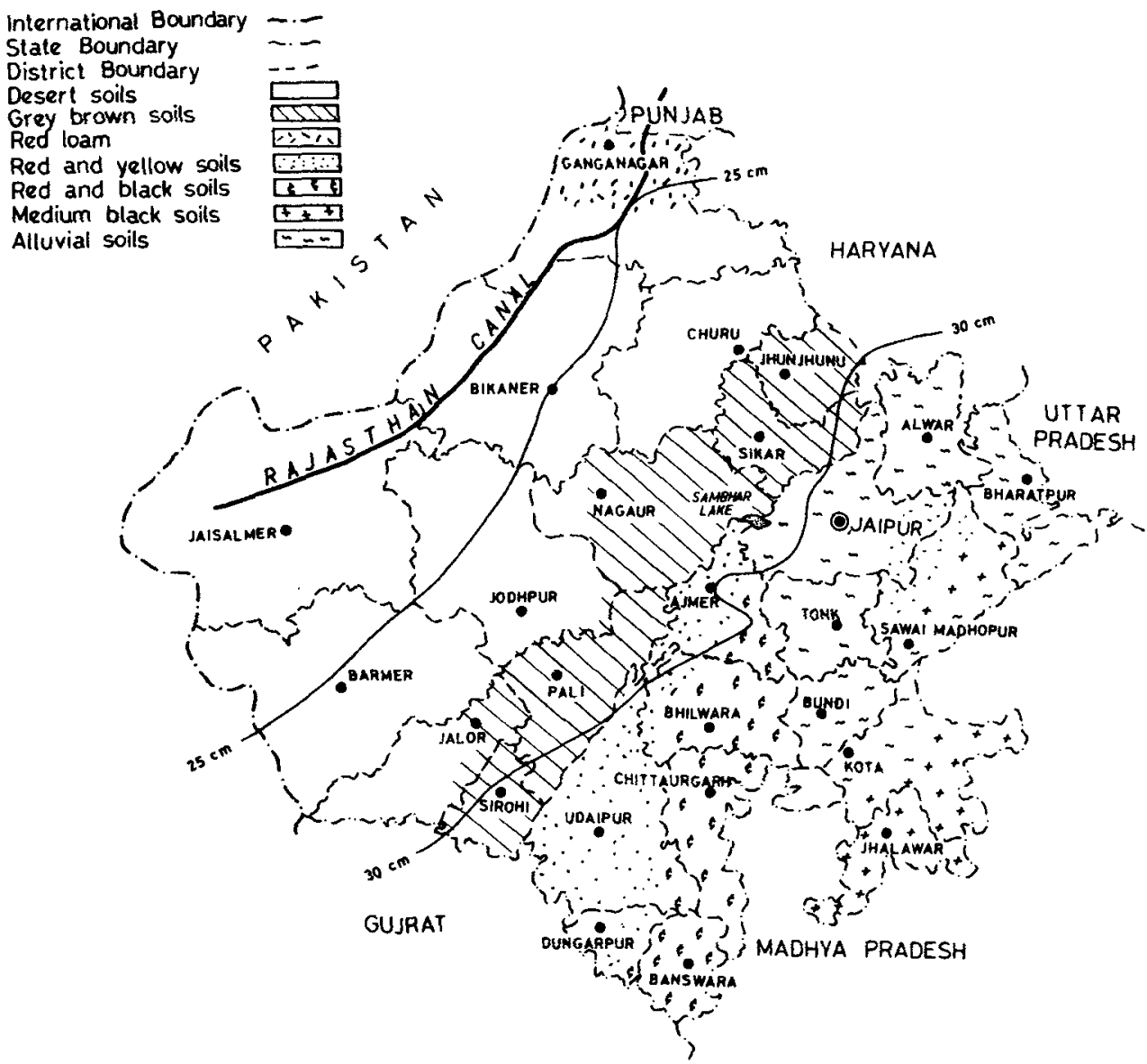

Figure 1. Map of Rajasthan showing soils and the Rajasthan canal.

comparison. Benefits per hectare of farm agriculture have been estimated as given in table 4 . In the table, data for citrus fruits and a possible multiple cropping pattern of three short-duration crops have also been included, although these crops presently are not amongst those adopted in the cropping pattern.

The project area is located in an ancient flood plain of the Indus river system. In recent geological times, the alluvial soils have been overlain and mixed with windblown sand resulting in a vast expanse of shifting sand dunes. About $20 \%$ of the command area of the canal has tal (saline/alkaline) soil which is amenable to reclamation through leaching. Most of the paddy, sugarcane and cotton included in the adopted cropping pattern of the project are expected to be grown on the tal soil.

\section{Policy issues}

One very important policy matter for the agricultural development of arid lands pertains to the level of technology (agriculture as well as irrigation) that should be used. 


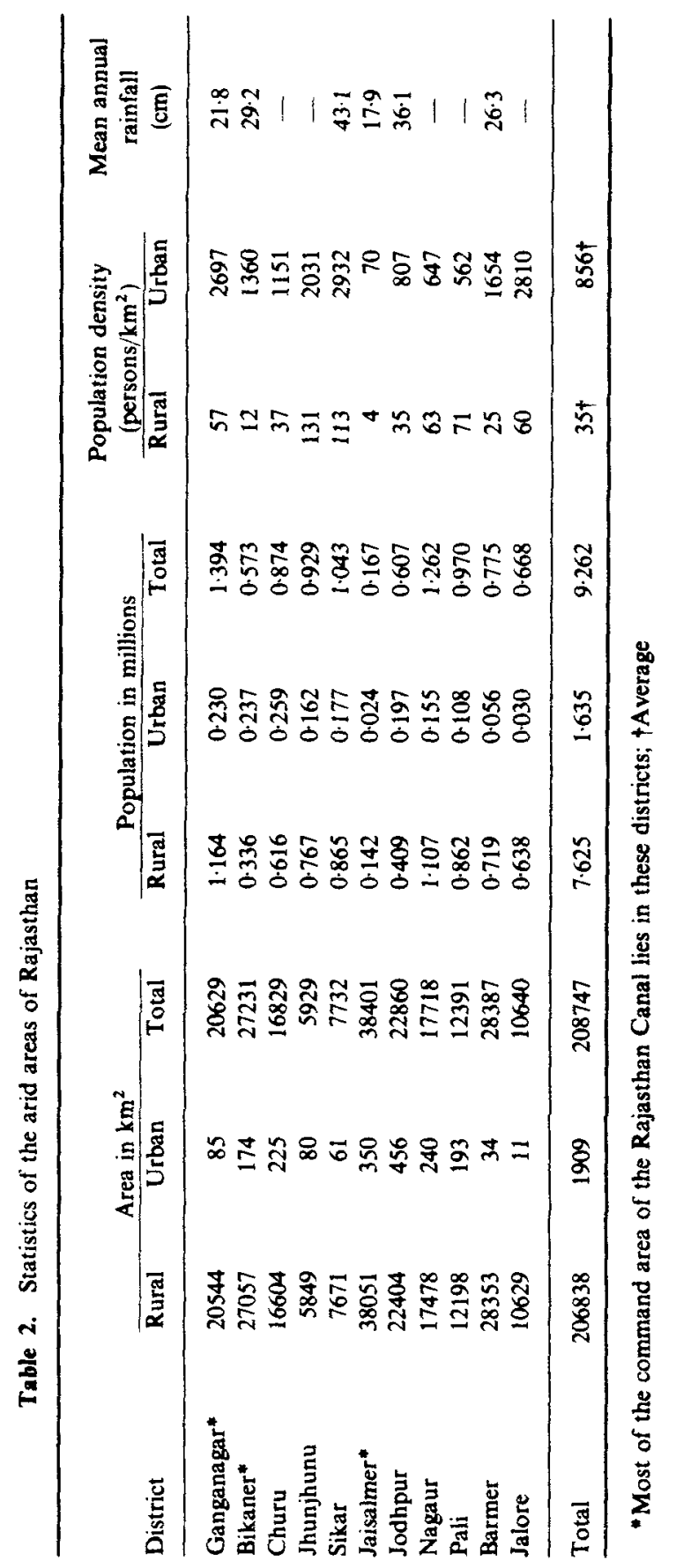




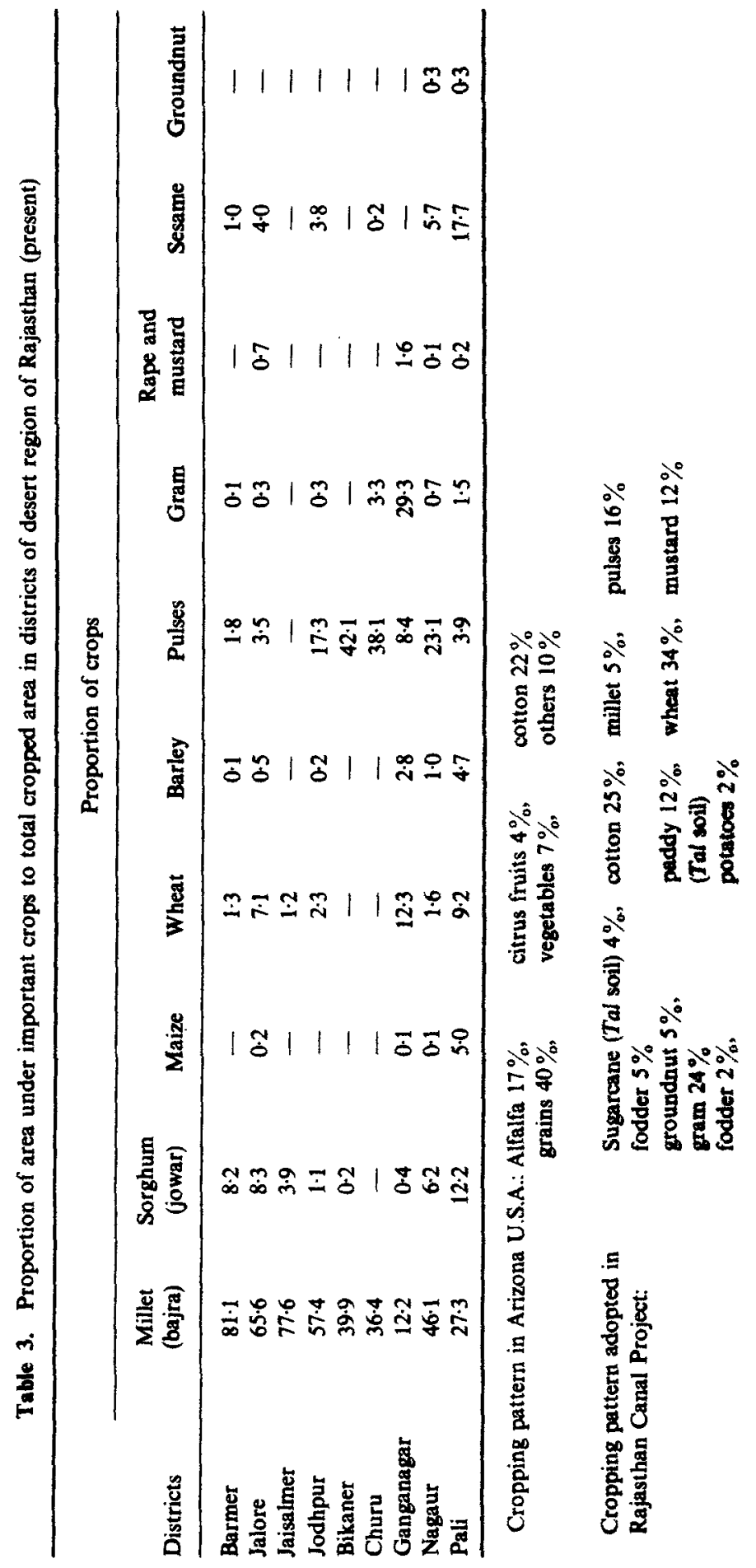




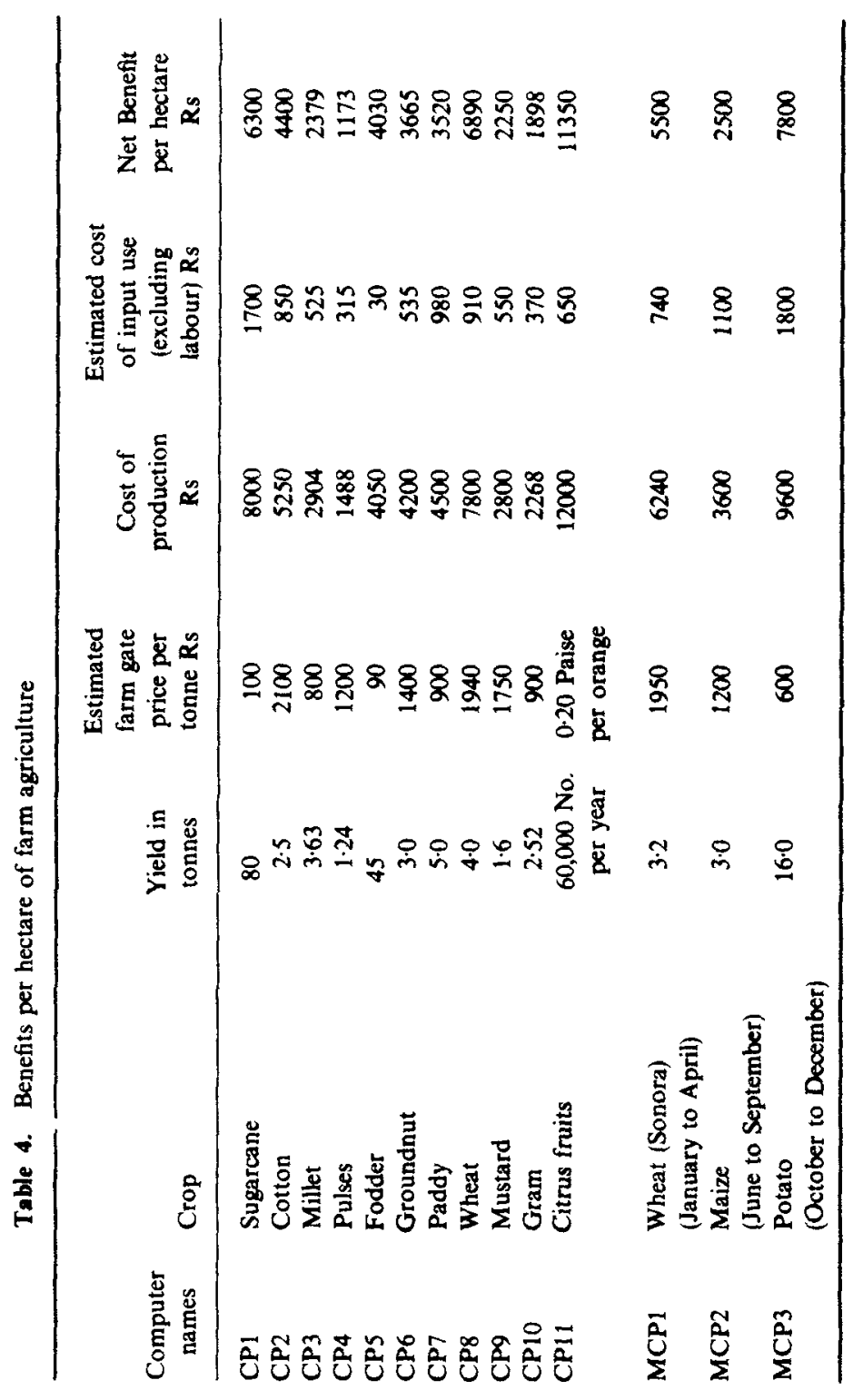


As will be discussed later, there are divergent views on this issue in literature.

Another important policy question pertains to the use of water. Water in an arid land can be used to meet the full irrigation requirements of the plants in a limited area thereby obtaining maximum crop yield per unit land area (assuming adequate supplies of other inputs) or the water could be used to meet only part of the irrigation requirements of the plants in a greater cropped area. The basic difference on this question between an arid and humid environment is that while in the case of the former, the plant will grow and survive only because of the water supplied from the irrigation system, the soil moisture in a humid environment may always remain above the permanent wilting point and therefore the plant can grow even without the use of irrigation water.

A third policy question deals with the appropriate size of land holdings in areas to be colonized. Should the holding size be large, small or some in-between size?

The fourth important policy area is that of the employment generated by the developments. As will be seen later, these four policy questions cannot be considered as separate issues. Choices in one area make large impacts in other areas.

\section{Study model}

The objective of this study is to evolve the effect of technology transfer on the total benefits of the project and on the agricultural income of the farmers after full project development has taken place and all the capital expenditure incurred initially has been recovered. Two parameters of the technology transfer were considered. One parameter was the level of technology used in improving the irrigation efficiency of the system. It was assumed that with the furrow or the border strip irrigation system, an irrigation efficiency of $70 \%$ could be achieved, while with the use of drip irrigation or sprinklers, an irrigation efficiency of 90 or even $95 \%$ may be quite valid. The other parameter considered was biological, that is, the effect of short-duration high-yielding varieties of seed (commonly used in multiple cropping) on the benefits of the project and on the income of the farmer. In addition, the possibility of growing citrus fruits was also considered.

A linear programming (LP) model to maximise the benefits from the cropping pattern in the 12 months with only the available water (and in some cases also the land) as constraints was used. Such models have often been used for determining optimum cropping patterns by Heady \& Nicol (1975) and others.

An LP model was used to maximize (i) benefits (ii) cropped area from a given fixed quantity of water in each of the twelve months of the year in the Rajasthan canal. The maximum benefits (or the maximum cropped area) and the optimum cropping patterns in the twelve months were determined with available water in the canal as the only constraints. Three levels of agricultural technology (giving high, medium, and low crop yields) and two levels of irrigation technology $(95 \%$ irrigation efficiency with sprinklers or drip irrigation and $70 \%$ irrigation efficiency with furrow or border strip irrigation) and with two strategies (maximize benefits or maximize cropped area) were used to determine the benefits, cropped area and the cropping pattern with water supplied to the plants equalling their consumptive requirements.

The objective function is

$$
\text { Maximize } Z=\sum_{j=1}^{m} p_{j} y_{j}
$$


subject to constraints of water and land, where $y_{j}=$ area of crops $(j=1,2, \ldots n)$ in hectares and $p_{j}=$ coefficient of return from a unit of land for each crop.

(i) Water constraint

$$
\sum_{i=1}^{12} x_{i j} y_{j} \leqslant X_{i} ; \quad i=1,2, \ldots 12
$$

where $x_{i j}=$ quantity of water required by one hectare of crop $j$ during month $i$ and $X_{i}$ $=$ volume of water available for irrigation in month $i$.

(ii) Land constraints

$$
\sum_{j=1}^{n} y_{j} \leqslant A
$$

where $A$ is the total area of land available

$$
y_{j} \geqslant 0 \text { for } j=1,2, \ldots n \text {. }
$$

The consumptive use water requirements for growing per unit crop area were determined by using climatic data and the monthly consumptive use coefficients of various crops given by Christensen (1968), Hargreaves (1956), Ministry of Agriculture (1970) and Ministry of Irrigation and Power (1971). The available water for the consumptive use was determined by allowing $10 \%$ loss in the main canal and its distributaries and $5 \%$ loss in the field water courses. In addition, allowance was made for the irrigation method assuming $95 \%$ irrigation efficiency for drip irrigation or sprinklers and $70 \%$ irrigation efficiency for furrow or border strip irrigation systems. The model also explored the case when the water supplied to the plants was only $60 \%$ of their consumptive requirements for high agricultural technology and for both levels of irrigation technology.

The benefits per unit crop area are given in table 4 and were obtained assuming crop yield with adequate use of fertilizers and assured supply of water. The labour cost was not considered as it was assumed that each unit of the farm can be managed by a farmer and his family. The agricultural labour requirements for each of the above cases for the full command area of the Rajasthan canal project as well as for farms of 4 and 6 ha area were also determined using farm management practices in India.

\section{Discussion of results}

\subsection{Agricultural technology}

Three levels of agricultural technology viz high, medium and low are considered in the study. High technology would involve assured supply of all inputs such as water, fertilizers, pesticides and the use of high yielding varieties (labour has not been considered at any level in this study as explained earlier in \$5). This would also require good agricultural management practices. The crop yield per unit area of land for high technology will be high. Low agricultural technology implies inadequate and inefficient use of essential inputs and use of poor agricultural practices. Medium technology indicates a midway position between high and low technologies. The crop yields and net benefits determined per hectare of agricultural land for various crops in the study 


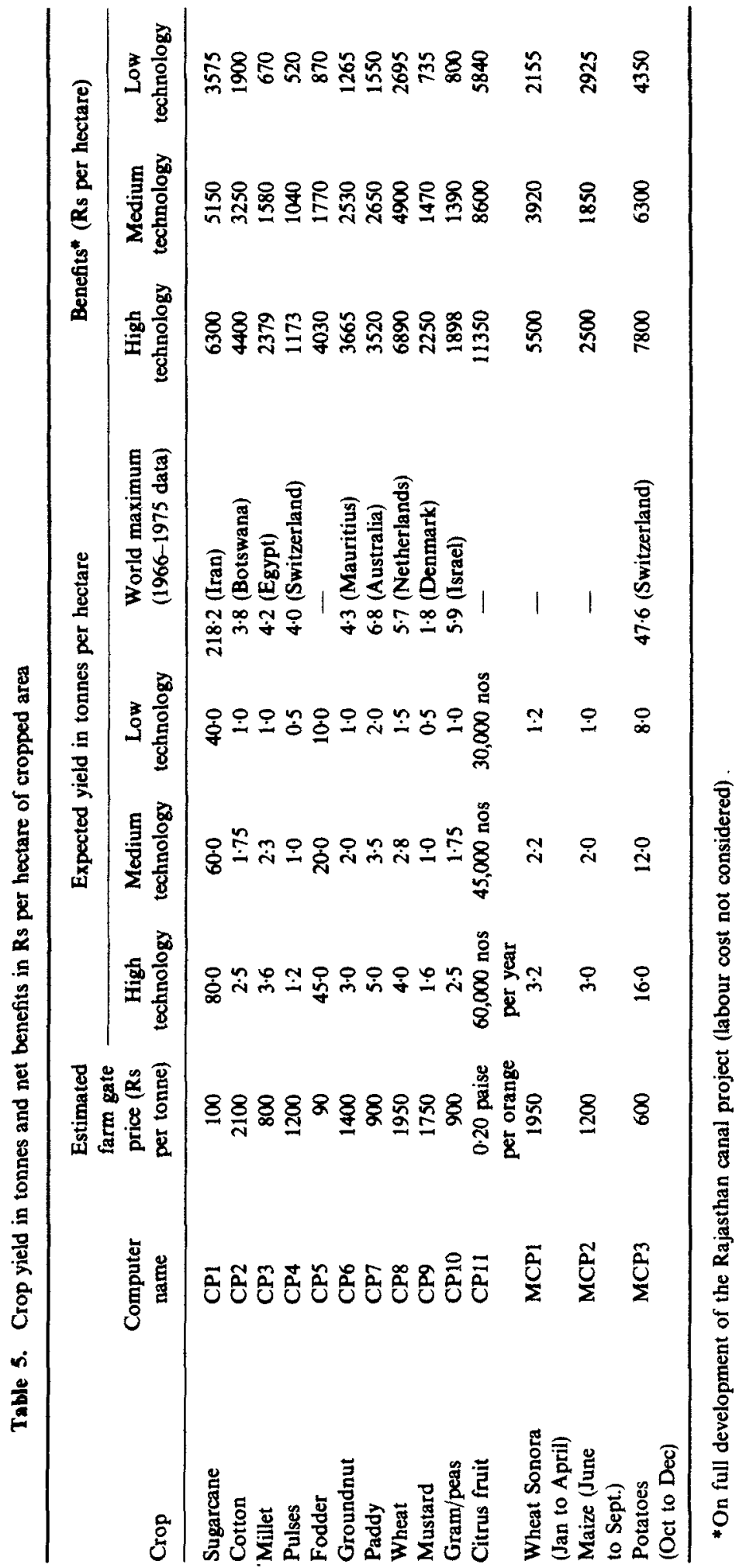




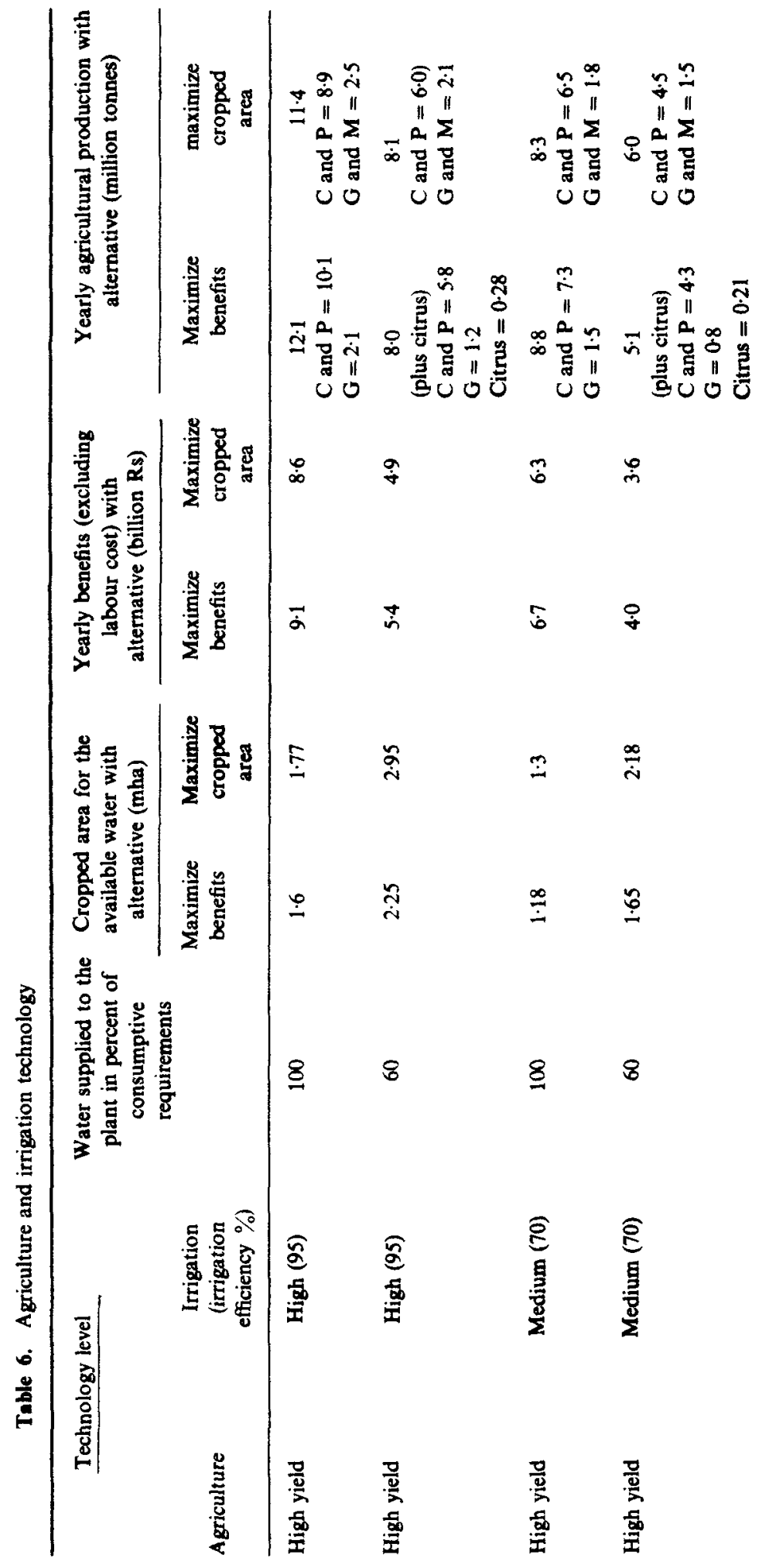


II

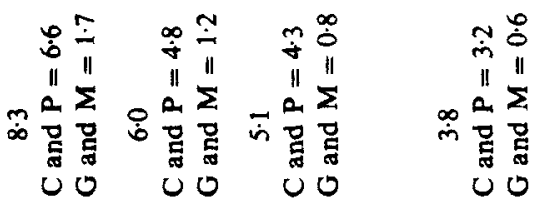

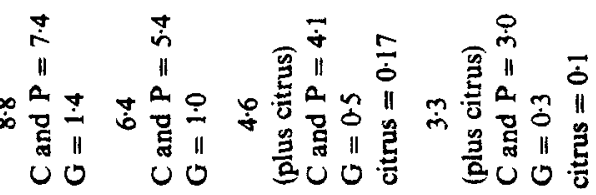

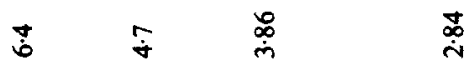

$\stackrel{\infty}{\dot{0}} \stackrel{\text { y }}{\dot{m}}$

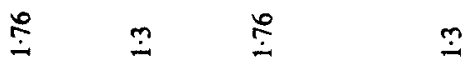

$\stackrel{\infty}{\dot{m}} \stackrel{⿱}{\dot{1}} \quad \stackrel{g}{\dot{g}}$

$8 \quad 8$

8

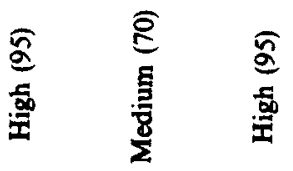

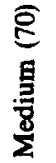

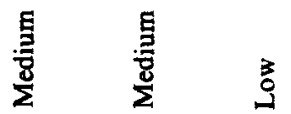

8

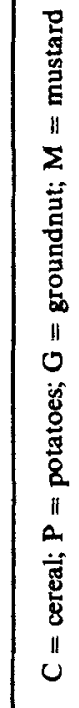


model, at the three levels of agricultural technology considered in the earlier studies, (Verma 1977a, b) are given in table 5 .

The results given in tables 6 and 7 indicate that the benefits from the canal water will be more than doubled if the agricultural technology level is changed from low to high, while they will be more than one and a half times if the change is from low to medium technology. The percentage increase in the total agricultural production is even more than the percentage increase in benefits for a change from low to medium or low to high technology. The strategy of maximizing benefits yields higher economic efficiency as compared to the strategy of maximizing cropped area. The yearly farm income is increased about three times (from Rs 8800 to Rs 22800 for a 4-ha farm and from Rs 13200 to Rs 34200 for a 6-ha farm) if the agricultural technology is improved from low to high and the strategy is changed from 'maximizing cropped area' to 'maximizing benefits'. The agricultural labour requirements remain the same for the three levels of agricultural technology (for the same irrigation technology) if the strategy used is of maximizing cropped area and if the water supplied to the plant equals its consumptive requirements. With the strategy of maximizing benefits the agricultural labour requirements increase with the improvement of the agricultural technology. If the total labour requirements are compared for the two strategies viz 'maximize benefits" and 'maximize cropped area' it is found that the difference is insignificant (when water supplied to the plant equals its consumptive requirement) for high and medium agricultural technology; however the difference is about $30 \%$ for low agricultural technology. For the price structure and the crop water requirements adopted in the study, the choice of crops in the optimum cropping pattern remains almost the same for the three technology levels.

Discussion of the policy issues of agricultural development in literature is dominated by a polarization of opinion on whether the principal objective of policy should be equity or efficiency. Hopper (1968) states the view that agricultural development policies should be based on the single-minded pursuit of the goal of increased output. He argues, particularly from the Indian context, that the production of food must be accepted as the priority objective. Hopper emphasizes that the development programmes should aim at the application of the latest in science and technology. On the other hand, Maass (1966) stresses on equity for agricultural development policies in developing countries. He suggests that government economic programmes intended to attain multiple objectives should be designed to achieve the desired distribution of income. Frankel (1969) and Ruttan \& Hayami (1973) explain the problem of income distribution with technology transfer in agricultural development; it has been pointed out that the technological change is likely to contribute to the widening income disparities among farmers. Johnston et al (1972) consider that the objectives particularly relevant to the design of strategies for agricultural development should be (i) contributing to the overall rate of economic growth and the process of structural transformation, (ii) achieving a satisfactory rate of increase in farm output at minimum cost, (iii) achieving a broad-based improvement in the welfare of the rural population and (iv) facilitating the process of social modernization. In other words, Johnston et al suggest that agricultural development policies should be directed at multiple objectives.

It seems that the main criticism against technology transfer for agricultural development in developing countries is that this transfer may lead to inequality in the income distribution of the farmers and thus may result in social and political problems. The reason for this criticism appears to be that the technology change may necessitate 


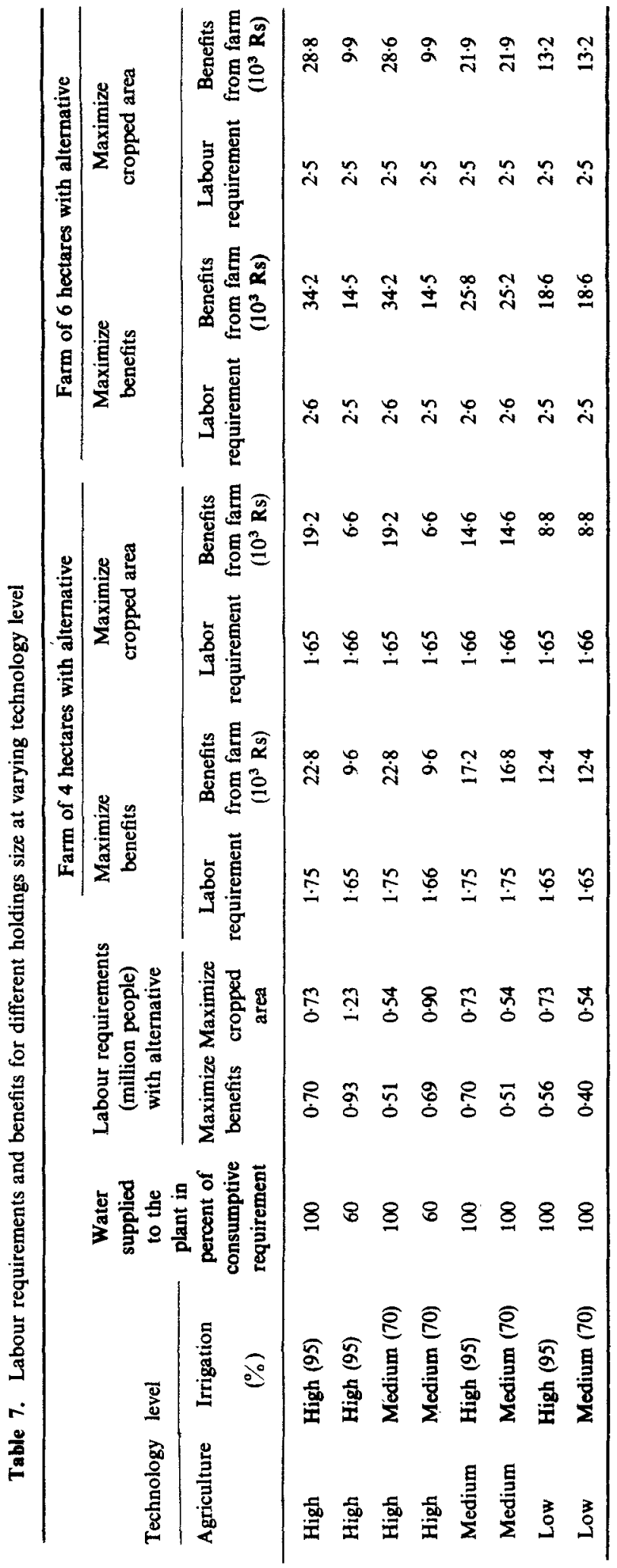


mechanization converting small holdings into bigger ones. However, mechanization is not necessary for the transfer of agricultural technology. The use of high-yielding varieties and good agricultural practices, choice of proper crops and adequate and efficient use of inputs do not require large holdings and use of agricultural machinery. Lau \& Yotopoulos (1971) have found by using a profit function of the CobbDouglas form and data derived from the farm management studies in India that the relative economic efficiency of small farms is higher than for large farms and that small farms attain higher levels of price efficiency and/or that they operate at higher levels of technical efficiency. The problem of income distribution can have an easy solution in the case of agricultural development of arid lands. Here the proper allocation of water among the various farmers can help in manipulating equity. In many cases the arid land may belong to the central or the state governments (as is the case for most of the command area of the Rajasthan canal project). In such situations proper settlement and water allocation policies will result in even distribution of income derived from technology transfer. The results of the Rajasthan canal project study indicate that if the size of holdings is changed from 6 to 4 ha for high agricultural technology the average yearly income of a farmer is reduced from Rs 34,200 to Rs 22,800 (which is still about double the income of a 6 ha farm with low technology) but the benefits of the technology change are made available to many more people (from 0.25 million people to 0.4 million people). Also agricultural tax reforms as suggested by Kaldor (1964) should greatly help even distribution of income amongst farmers as a result of technology transfer.

The results of the Rajasthan canal project presented in this paper clearly show that the agricultural development policies of arid lands should be based on intensive agriculture and on maximizing benefits with modern technology.

\subsection{Irrigation technology}

The results given in tables 6 and 7 consider two levels of irrigation technology (i) high, with an irrigation efficiency of about $95 \%$ using sprinklers or drip irrigation systems and (ii) medium with irrigation efficiency of about $70 \%$ with furrow or border strip irrigation systems. The results indicate that when the irrigation technology is improved from medium to high the total benefits at every level of agricultural technology also increase by about $40 \%$. The total agricultural production also increases by almost the same percentage. This increase in benefits and production is the result of more water becoming available, making it possible to increase the irrigated crop area. In the case of the Rajasthan canal project it was assumed that assured and known quantities of water are available in the canal for each of the 12 months of the year. If this water is not assured, as for example in the case of dry land farming or groundwater development, the scope of improvement in irrigation technology would not be limited only by the additional quantity of water available at a certain location but also by its reliability in time and space. In this context the point stressed by Levine (1970) regarding the importance of better coordination between the operation of irrigation systems and the farmer's use of the available water and the need for improving on-farm water management practices is very significant.

A change from the furrow or border strip irrigation system to sprinklers or the drip irrigation system would require additional capital. Most of the cases of improvement in irrigation technology are capital-intensive. However, since water has a very high 
economic value in arid lands the capital expenditure in improving irrigation technology is usually paid off. The experiences of sprinklers or drip irrigation systems in parts of Israel and Arizona indicate that the capital expenditure is recovered by the farmers in about 5 to 10 years. The same seems to be applicable for the Rajasthan canal project.

The importance of improving irrigation technology in an arid land should not be underestimated. This may bring even higher dividends as compared to the improvement in agricultural technology (e.g., the results indicate that the yearly benefits as well as the agricultural employment from the Rajasthan canal project with medium agriculture technology and high irrigation technology are greater than with high agriculture technology and medium irrigation technology).

\subsection{Water-use of less than full consumptive requirement}

The fixed quantity of water available in the canal can be used to meet the full consumptive water requirements of the plants in a limited area thereby getting maximum crop yield per unit area or this could be utilized for a greater cropped area with water use by the plants per unit area being less than their consumptive requirements and thus, with crop yields less than the maximum. This policy question was looked into by determining the benefits and agricultural employment opportunities for the high agricultural technology (using both the strategies of maximizing benefits and maximizing cropped area) for two cases (i) water supplied to the plants is for $100 \%$ of their consumptive requirements and (ii) water supplied to the plants is for only $60 \%$ of their consumptive requirements. The results indicate that when the water supplied to the plants was for only $60 \%$ of their consumptive requirements the total benefits of the Rajasthan canal project were reduced to about $40 \%$ while the cropped area of the project increased by about $50 \%$. If the additional cost required in developing on-farm works for the increased cropped area is taken into account, the total benefits of the project with water use of $60 \%$ of the consumptive requirements should be less than half of what these will be if full consumptive requirements of the plants are satisfied from the canal water. The agricultural labour requirements increase from about 30 to $70 \%$ (from 0.7 million to 0.9 million with the strategy 'maximize benefits' and from 0.7 to 1.2 million with the strategy 'maximize cropped area') due to the increased cropped area. However, by using less water per unit cropped area farm benefits are reduced to about one-third from Rs 28,000 to Rs 9900 for a 6-ha farm and from Rs 19,200 to Rs 6,600 for a 4-ha farm (the reduction will be even more significant if the costs of farm-development works for increased cropped area are considered). These results clearly indicate that in an arid land if the water is spread too thinly even with the good intention of increasing cropped area thereby benefitting more people, this will result in highly inefficient use of a very scarce resource. It will be like going from a production level to a subsistence level for the farmers. On the other hand, Collinson (1972) while analyzing the rural-based African economies found that improved productivity requires the orientation of resources from subsistence to production for the market. In developing countries where in addition to water, land may also be a limiting factor the policy of increasing cropped area at the cost of getting significantly lower benefits and lower agricultural production will be dangerous. Statistics of land area and the GNP per capita of some countries are given in table 4. These data indicate that India is not only very low in GNP but its available area per capita $(0.59 \mathrm{ha})$ is one of the lowest in the world. This suggests that on a long-term basis land will also become a 
limiting factor for the economic growth of the country and therefore the conclusions of Hopper (1968) that "the poor countries can feed themselves if their agriculture is modernized and their rural economies are restructured. That requires infusions of technology and capital from rich nations" is very pertinent in formulating policies for the agricultural development in India and particularly in the arid lands of India.

\subsection{Employment potential and farm size}

The agriculture labour requirements for various levels of agricultural and irrigation technologies were also determined using data from farm management practices in India. The results given in table 7 indicate that an additional $25 \%$ labour requirement (from 0.4 to 0.51 million people for $70 \%$ irrigation efficiency and from 0.56 to 0.70 million people for $95 \%$ irrigation efficiency) is generated with a change in agriculture technology from low to medium. The impact of changing irrigation technology from medium to high on agricultural employment potential is even more significant as the results indicate an increase of about $40 \%$ (from 0.4 to 0.56 million people for low agricultural technology and from 0.51 to 0.7 million people for medium and high agricultural technologies). These results suggest that if increasing employment potential is an important objective of agricultural development in an arid area then irrigation facilities should be provided to more areas and atleast medium agricultural technology should be used.

In the absence of farm mechanization, as has been assumed in this study, the size of holding for colonization will depend upon the technology level and upon the economic expectations of the farmers. For example, if on full development of the project, it is aimed that a farmer should have an annual income of atleast Rs 22,000/-, this can be achieved either with a 6 ha farm with medium agricultural technology or with a 4 ha farm holding with high agricultural technology (refer table 7).

\section{Conclusions}

Agricultural development policies in arid lands should be based on the principle of maximizing benefits and/or agricultural production. High agricultural and irrigation technologies should be used to maximize benefits/production per unit of water and land area. Proper settlement, water allocation and agricultural tax policies will help in achieving equity amongst the farmers. Intensive agriculture at high technology levels will result in higher economic efficiency as well as opportunities for higher agricultural employment.

\section{References}

Anon 1977 The New York Times April 14, A5

Christiansen J E $1968 \mathrm{~J}$. Irrigation and Drainage Division ASCE 94: 243-263

Collinson M P 1972 A handbook for rural development Planning in Africa (Preger Publishers) p. 15

Domenico P A, Anderson D V, Case C M 1968 Water Resources Res. 4: 247-255

Frankel F R 1969 J. Asian Studies 692

Hargreaves G H $1956 \mathrm{~J}$. Irrigation and Drainage Division ASCE 1105

Heady E O, Nicol J K 1975 Water Resources Res. 11:

Hopper W D 1968 in Strategy for the conquest of hunger (New York: Rockefeller Foundation)

Johnston B F, Page Jr J M, Warr P 1972 Studies in agricultural economic trade and development 11: 28 
Kaldor N 1964 Essays on economic policy (Gerald Duckworth) 1: 216

Kelso M M, Martin W E, Mack L E 1973 Water supplies and economic growth in an arid enwiromment; An Arizona case study (Tucson: The University of Arizona Press) p. 225

Lau L J, Yotopoulos P A 1971 Am. Eco. Rev. 61(1) 94-109

Levine G 1970 The water environment and crop production, Paper presented at the Cornell Workshop on some emerging issues accompanying recent breakthrough in food production, Ithaca N.Y. 1970

Maass A 1966 Q. J. Econ. 214

Ministry of Agriculture, Water Management Division, New Delhi 1970 A guide for estimating irrigation water requirements, Tech. Ser. No. 2, 8: 39

Ministry of Irrigation and Power 1971 Dynamics of shifting sand dunes in Western Rajasthan and its stabilization, CWPC No. 262, Central Water and Power Commission, Government of India, New Delhi

Ministry of Irrigation and Power 1972 Report of the Irrigation Commission, New Delhi 2: 342

Rao K L 1975 India's water wealth-its assessment, uses and projections (New Delhi: Orient Longman) p. 204

Ruttan V W, Hayami Y 1973 Technol. Cult. 14: 119

Verma R D 1977a Technology transfer for irrigation planning of arid lands, Paper presented at the Socond Int. Conf. transfer of water resources knowledge, Colorado State University, Colorado.

Verma R D 1977b Technology transfer for irrigation planning of arid lands (case study of Rajasthan Canal Project), Research Report and Seminar Papers of the Centre for Population Studies, Harvard University, Cambridge

Wiener A 1964 Development and management of water supplies under conditions of scarcity of resources, three lectures P N 422 